\title{
Introducing Skills-Based Teaching to Mongolia
}

\author{
Burgess, A. ${ }^{1}$, Jeffery, H.E. ${ }^{2}$, Hill, D.A. ${ }^{3}$, Black, K.I. ${ }^{4}$
}

\begin{abstract}
Background: In Mongolia, the maternal and infant mortality rate is relatively high compared to countries with similar service coverage. As part of a curriculum review of Obstetrics, Gynaecology and Neonatology for the Mongolian National University of Medical Sciences, six senior Mongolian delegates, sponsored by the United Nations Population Fund, attended a one week program at Sydney Medical School, Australia. The purpose of the program was to demonstrate best practice in medical education, and in particular, to highlight student-centred approaches to learning and teaching. The SCORPIO (Structured, Clinical, Objective, Referenced, Problem-oriented, integrated and Organised) system of teaching was demonstrated, with the Mongolian delegates participating.
\end{abstract}

Methods: At the end of the SCORPIO session, the Mongolian delegates were asked to complete a questionnaire regarding their perceptions of the SCORPIO learning experience. Both closed items and open-ended questions were included.

Results: All participants $(\mathrm{n}=6)$ found SCORPIO as a method of teaching to be highly acceptable. All felt that SCORPIO enabled the provision of an excellent method of teaching from multidisciplinary professionals, immediate feedback, and small group active learning within an authentic context. While there were no negative aspects reported of the experience by the participants, they did anticipate logistical difficulties to implementation in their own country.

Conclusion: Participants appreciated the value of the SCORPIO method of skills training and appreciated the role of active participation and the provision of immediate feedback on performance. In-country roll-out of the method may be limited by lack of academic staff, space and the persistence of a culture of didactic, rather than interactive teaching.

\section{Background}

In Mongolia, the maternal and infant mortality rate is relatively high compared to countries with similar service coverage. The Government of Mongolia has highlighted the need to reduce maternal and infant mortality, with new born deaths accounting for $57 \%$ of the under 5 mortality (National Statistical Office, 2013).

\footnotetext{
${ }^{1}$ Sydney Medical School - Education Office, Sydney Medical School, The University of Sydney, Australia

${ }^{2}$ Sydney School of Public Health, Sydney Medical School,

The University of Sydney, Australia

${ }^{3}$ Education Consultant, Sydney, Australia

${ }^{4}$ Sydney Medical School - Central, The University of

Sydney, Australia

Corresponding Author:

Annette Burgess

Sydney Medical School - Education Office,

Sydney Medical School, The University of Sydney,

Sydney, NSW, Australia
}

Email: annette.burgess@sydney.edu.au
Improvements to the quality of medical education and training for future medical practitioners are essential to improved health outcomes for women and children. However, medical education in Mongolia faces a number of challenges, including a culture of teachercentred learning approaches, the capacity of the healthcare workforce, and the limited clinical experience made available for medical students, despite a large number of private and public hospitals.

In March 2014, as part of a curriculum review of the Obstetrics, Gynaecology and Neonatology for the Mongolian National University of Medical Sciences (MNUMS), six senior Mongolian delegates, sponsored by the United Nations Population Fund (UNFPA) Mongolia, attended a one week program at Sydney Medical School. The purpose of the program was to demonstrate best practice in undergraduate medical education within Obstetrics, Gynaecology and Neonatology, and in particular, to highlight student-centred approaches to learning and teaching. A number 
of modern teaching methods were demonstrated, including the SCORPIO system of teaching.

SCORPIO is an acronym denoting that the education is: Structured, Clinical, Objective, Referenced, Problem-oriented, Integrated and Organised. The SCORPIO system provides a student-centred, active method of teaching clinical skills. It combines both didactic and interactive teaching (Hill, 1992; Hill, 1997). Use of the SCORPIO system of teaching has the ability to successfully address many elements crucial to student-centred learning and teaching. It has the capacity to bring resources, including equipment and teachers, together in a comprehensive and organised way. Due to its previous success in changing workplace practices in low/middle income (Jeffery et al., 2004; Hirst et al., 2009) the SCORPIO system of teaching was demonstrated, with the expectation that this method of teaching would be adopted in Mongolia to teach medical students and update medical practitioners to current evidence-based medical practices.

The aim of this study was to explore the Mongolian delegates' perceptions of participation in the SCPOPIO.

\section{Methods}

The Obstetric and Neonatal Care SCORPIO training program took place at Sydney Medical School, Royal Prince Alfred Hospital over a one day period. Six senior Mongolian delegates, with training backgrounds in either medicine or dentistry, participated in the session; three had an obstetric background. In order to add to the authenticity of the session, six final year medical students also participated. SCORPIO teaching was based on a module consisting of three essential components:

\section{Study Guide and Introduction \\ 2. Teaching Stations \\ 3. Formative Assessment}

\section{Study Guide and Introduction}

Participants were provided with copies of the lectures and station resources. The SCORPIO started with a 20 minute lecture and demonstration to the whole group, setting the scene for the subsequent teaching stations and reminding participants of key principles of the topics. Essential knowledge which was needed in application during the rest of the day was presented, and participants were free to ask questions for the purpose of clarification.

\section{Teaching Stations}

Participants were divided into two groups of six in order to rotate through each of the four SCORPIO stations. Each group consisted of three final year medical students, and three Mongolian delegates. Stations included: 1) Post-partum haemorrhage (PPH); 2) Normal vaginal delivery (NVD); 3) Newborn Anthropometry; 4) Resuscitation of the neonate (Figure 1).

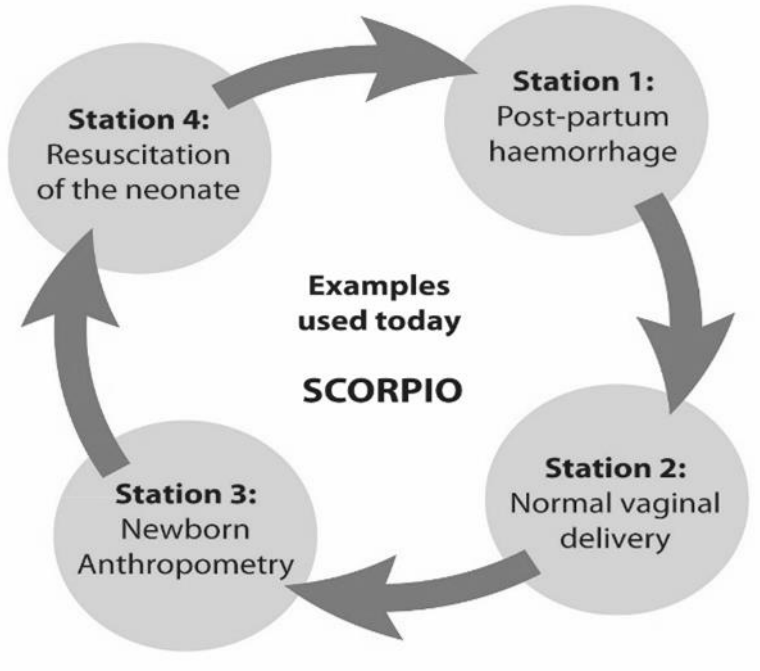

Figure 1: SCORPIO stations

Each station was facilitated by a Registered Nurse (Midwife) or a Neonatologist, or an Obstetrician and Gynaecologist. Each facilitator had high level skills and knowledge in their area of expertise. Each station was structured to teach a specific skill using a sequence of "tell, show, do, feedback" over 30 minutes. The knowledge and skills to be gained from the course were set out clearly as objectives. Each station focused on a different aspect of the topic and had its own clearly defined objectives. Teamwork, excellence in communication, sensitivity to women and babies were important components of all topics, which should underpin good clinical practice.

\section{Formative assessment}

Formative assessment was used to confirm that mastery of the skill and acquisition of knowledge had been achieved. Participants were assessed with a written test, a quiz and a practical test. The practical test was in Objective Structured Clinical Examination (OSCE) format. 


\section{Data collection and analysis}

At the end of the SCORPIO session, the Mongolian delegates were asked to complete a questionnaire regarding their perceptions of their learning experience. Participants were asked to respond to seven closed questions, such as "I found the presentation technique to be useful" using a five-point Likert scale ranging from 'strongly disagree' (1) to 'strongly agree' (5). Survey questions were based on Brookfield's Critical Incident Questionnaire, which was designed to provide significant feedback on participant experiences in the learning environment (Brookfield, 1995). Participants were also asked, on scale of 1 to 10 , to rate how likely they would be to recommend SCORPIO as a means of teaching to their colleagues. Additionally, two openended questions were included in the questionnaire, asking what the best features of SCORPIO were, and areas that need improvement. Data were analysed using descriptive statistics (Creswell, 2002).

Ethics approval was obtained for The University of Sydney Human Research Ethics Committee.

\section{Results}

All Mongolian delegates $(n=6)$ completed the questionnaire. Responses to closed items are displayed in Figure 2. Participants found SCORPIO as a method of teaching to be highly acceptable. Participant responses to openended questions are summarised in Table 1. Responses regarding the best features of the SCORPIO fell into three key areas:

1) excellence in teaching from multidisciplinary professionals with immediate feedback;

2) small groups, active participation; and

3) authentic context.

While there were no negative aspects reported to be experienced by the participants, they did anticipate logistical difficulties implementation of the SCORPIO in their own country.

On a scale of one to ten, 2 delegates rated " 8 ", one delegate " 9 ", and 3 delegates " 10 " to indicate the likeness that they would recommend SCORPIO as a method of teaching to their colleagues.

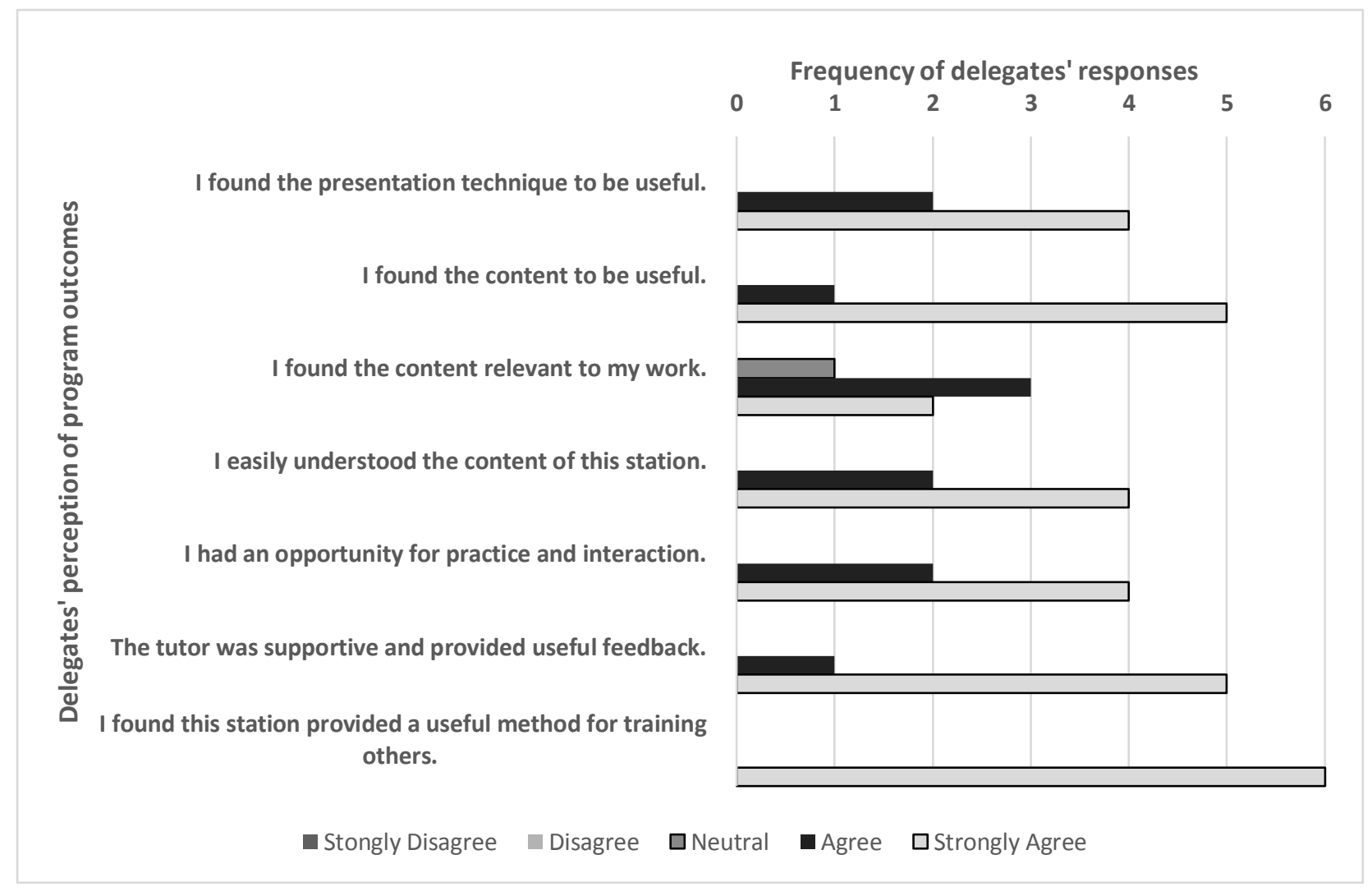

Figure 2: Mongolian delegates' responses to questionnaire 
Table 1: Participant responses to open ended questions regarding their perceived best and worst features of the SCORPIO

What was the best feature of the SCORPIO?

- Multidisciplinary, with every lecturer explaining a subject (PPH, NVD, Resuscitation, Anthropometry)

- $\quad$ Training and Teaching method, that is, tell, show, do and feedback

- Active involvement from all participants

- Innovative, organised, time-saving, objective

- The authentic environment, with real instruments and a setting close to the hospital setting

- Provision of feedback

- One can also evaluate the teacher

What was the worst feature of the SCORPIO?

- $\quad$ Logistic wise may be difficult in Mongolia

\section{Discussion}

This study aimed to explore the Mongolian delegates' perceptions of their experience of taking part in SCORPIO teaching in Obstetrics, Gynaecology and Neonatology. Participants found SCORPIO as a method of teaching to be highly acceptable. Participant responses regarding the best features of SCORPIO fell into three key areas: 1) small groups, active participation; 2) excellence in teaching from multidisciplinary professionals with immediate feedback; and 3) authentic context. While there were no negative aspects reported to be experienced by the participants, they did anticipate logistical difficulties to implementation of the SCORPIO in their own country.

\section{Small groups, active participation}

Learning is an active process, with the teacher acting as a facilitator, guiding the processing of information through interplay between existing and new knowledge (Spencer, 2003). For new knowledge to be actively acquired, opportunities for practice must be provided (Kaufman et al., 2000). Participants valued the small group teaching and learning methods that SCORPIO facilitated, and most participants commented that the best feature of SCOPRIO was the opportunity afforded for participation. Active learning pedagogies that engage students provide both cognitive and metacognitive benefits, leading to a deeper understanding of knowledge and greater knowledge retention (Graffam, 2007). Educational strategies that involve active professional participation which are closely linked to clinical decision making, are more likely to be linked to change (Grimshaw \& Russell, 1994). For students to learn, they need to be given meaningful opportunities for participation (Morris, 2012), and our participants recognized the educational benefits that occurred through active learning before, during and after each station. During the SCORPIO, participants were given multiple opportunities to observe the performance of others, which may allow them to improve their own performance by virtue of observation.

\section{Excellence in teaching from multidisciplinary professionals, and provision of feedback}

During the SCORPIO, the presence of expert teachers was valued. Learning occurs through observation, imitation and modelling of the teacher (Hesketh et al., 2001). Of these, the most powerful variables in the education setting is the tutor. Globally, the demands of health care systems have placed increased strains on clinicians' commitments to teaching. The SCORPIO demonstrated that various health professionals, including midwives, could successfully teach medical students. It is possible that seeing midwives teach doctors gave the Mongolian delegation a greater appreciation of the potential teaching roles of nursing staff in Mongolia, and the benefits of utilizing and pooling these resources. Additionally, the midwives, Neonatologists and Gyanecologists/ Obstetricians offered invaluable experience.

The direct observation of skills performance in the SCORPIO, allowed for accurate and constructive feedback for participants (Vickery 
\& Lake, 2005). Formative feedback to guide improvement in knowledge and skills should not be underestimated (Mehta, 2013). Participants' responses to closed questions indicate that the teachers' support and feedback given during the sessions was highly valued. Although feedback received within medical education can be vague and ineffective (Vickery \& Lake, 2005), the principles of small group learning within the SCORPIOs provided frequent opportunities for feedback from experienced teachers (O'Malley et al., 2003). Provision of meaningful feedback is one of the few ways that students can determine their progress, and make improvements (Cantillon \& Sargeant, 2008).

\section{Authentic environment}

Knowledge and understanding is more readily developed when explained and demonstrated within the relevant clinical context (Cooke et al., 2006). However, the increased focus on patient safety and quality of care, and limited availability of clinical supervisors, often leads to students spending more time as passive observers, rather than active participants. The formal, organized, structured and clinically relevant context of the SCOPRIO assisted in providing an authentic learning experience for participants. Active learning, with an alignment of the individual learners' needs promotes the development of proficiency in skills (Cooke et al., 2006). Motivation to learn is reduced once participants feel that learning is so complex that competence may not be readily achieved (Ryan \& Deci, 2000). Participants felt that the content delivered using the SCORPIO method of teaching was relevant and helpful, with essential curriculum components.

In order to assist in the implementation of SCORPIO as a new teaching methodology, and to develop teaching skills of staff within the Mongolian National University of Medical Sciences, a University of Sydney team visited Mongolia to provide further facilitator training in Mongolia. Here, two of the authors, HJ (Neonatologist) and KB (Gynaecologist and Obstetrician) provided similar in-country training on the SCORPIO. Again, both students and staff participated in the SCORPIO, and in addition, we provided teaching on key concepts of educational principals. The reason for providing in-country teaching was to lead and encourage change within the Mongolia universities and teaching hospitals; emphasize the importance neonatology teaching; and assist in breaking down anticipated barriers to implementation of student-centered learning and teaching methods.

\section{Limitations}

A limitation of this research is the small sample size of SCORPIO participants. Nevertheless, there were advantages to the choice of senior Mongolian delegates as potential change agents who actively experienced the teaching method and interacted with University of Sydney medical students at each station. Lacking was a senior Mongolian Paediatrician, in particular a Paediatrician with neonatal training, a reflection of the need for development of neonatology in Mongolia (UNICEF, 2013).

Unfortunately, we were not able to carry out a follow-up of in-country final implementation with the Mongolian doctors as teachers, and to assess the fidelity of this teaching method. While this was our intention, we were unable to gain further funding to do so.

\section{Conclusion}

Participation in the SCORPIO encompassed a broad, active, learning process. SCORPIO engaged participants through small group, learner-centred teaching methods, with opportunities to apply knowledge and skills. Expert tutors were engaged in the process, and the participants modelled the process demonstrated by the disciplinary expert, constructing clinical knowledge for themselves. Participants appreciated the unique insight and understanding of skills that is developed through active participation and the provision of feedback. Implementation of the SCORPIO method in Mongolia faces both cultural and logistical barriers.

\section{References}

Brookfield, S. (1995) Becoming a Critically Reflective Teacher, San Francisco, CA, USA: JosseyBass.

Creswell, J. (2002) Educational Research: Planning, Conducting and Evaluating Quantitative and Qualitative Research, Upper Saddle River, NJ, USA: Merrill.

Cooke, M., Irby, D. \& Sullivan, W. \& Ludmere, K.M. (2006) American medical education 100 years after the Flexner report, New England Journal of Medicine, 355, 13, pp. 1339-1344.

Cantillon, P. \& Sargeant, J. (2008) Giving feedback in clinical settings, BMJ, British Medical Journal, 337:a, p. 1961.

Graffam, B. \& Biggs, J. (2007) Active learning in medical education: strategies for beginning implementation, Medical Teacher, 29, 1,pp. 3842. 
Grimshaw, J.M. \& Russell, I.T. (1994) Achieving health gain through clinical guidelines II: ensuring guidelines change medical practice. Quality in Health Care, 3, 1, pp. 45-52.

Hill, D.A. (1997) A strategy for teaching and learning in the PBL clerkship, Medical Teacher, 19, 1, 2428.

Hill, D.A. (1992) SCORPIO: A system of medical teaching, Medical Teacher, 14, 1, pp. 37-41.

Hesketh, E.A., Bagnall, G. \& Buckley, E.G. (2001) A framework for developing excellence as a clinical educator, Medical Education, 35, 6, pp. 555-564.

Hirst, J.E., Jeffery, H.E., Morris, J., Foster, K. \& Elliot, EJ. (2009) Application of evidence-based teaching in maternal and child health in remote Vietnam, International Journal of Gynaecology and Obstetetrics, 104, 2, pp. 152-155.

Jeffery, H.E., Kocova, M., Tozija, F. Gjorgiev, D. Pop-Lazarova, M., Foster, K., Polverino, J. \& Hill, D.A. (2004) The impact of evidence-based education a perinatal capacity-building initiative in Macedonia, Medical Education, 38, 4, pp. 435-447.

Kaufman, D.M., Mann, K.V. \& Jennett, P. (2000) Teaching and Learning in Medical Education: How Theory can Inform Practice, London, UK: Association for the Study of Medical Education.

National Statistical Office of Mongolia, Social Indicator Sample Survey (SISS), (2013) Key Findings., June, 2014, Available at: http://www.childinfo.org/files/Mongolia_2013_SI SS_Key_Findings_Report_Eng.pdf [Äccessed 13 August 2015].
Morris, C. (2012) Replacing 'the firm': re-imagining clinical placements as time spent in communities of practice, In. Cook, V., Daly, C. \& Newman, M. [Eds.] Work Based Learning in Clinical Settings - Insights from Socio-Cultural Perspectives, Oxford, UK: Radcliffe Medical.

Mehta, N. (2013) Just imagine: new paradigms for medical education, Academic Medicine, 88, 10, pp. 1418-1423.

O'Malley, K.J., Moran, B.J. \& Haidet, P. (2003) Validation of an observation instrument for measuring student engagement in health professions settings, Evaluation \& the Health Professions, 26, 1, pp. 86-103.

Ryan, R.M. \& Deci, E. (2000) Self-determination theory and the facilitation of intrinsic motivation, social development, and well-being, American Psychologist, 55, 1, pp. 68-78.

Spencer, J. (2003) Learning and teaching in the clinical environment, BMJ, British Medical Journal, 326, pp. 591.

United Nations Children's Fund:UNICEF (2013) Mongolia, Supporting health and nutrition actions, Available at: http://www.unicef.org/ mongolia/2145_21839.html [Accessed 14 August 2015.]

Vickery, A.W. \& Lake, F.R. (2005) Teaching on the run tips. 10: Giving feedback, Medical Journal of Australia, 183, 5, pp. 267-268. 